\title{
EMPLOYEE'S LEARNING IN THE ORGANIZATION - A STUDY OF KNOWLEDGE BASED INDUSTRIES
}

\author{
Ravindra Hewa KURUPPUGE*, Ales GREGAR** \\ Tomas Bata University in Zlin, Faculty of Management and Economics \\ Department of Management and Marketing, Zlin, CZECH REPUBLIC \\ *e-mail: kuruppuge@yahoo.com \\ **e-mail: gregar@fame.utb.cz
}

\begin{abstract}
This paper focuses on reviewing the learning behavior of individual employees in the firm over other influencing factors in knowledge-based industries in Sri Lanka. Using a stratified random sampling technique, a sample of 143 employees from jobs in Database Administration \& Development, Systems \& Network Administration, Web Development \& Programming and Software Engineering was selected as respondents for the survey from 13 knowledge based industrial firms in Sri Lanka. After a descriptive analysis of the characteristics of respondents, the causal relationships among predictor and outcome variables were tested using the partial least squares regression method. The results indicated that the use of digital methods, digital tools, organizational identification and knowledge sharing are positively influenced by employee's learning in the firm. Yet, the employee's turnover intention has negatively influenced employee learning.
\end{abstract}

Keywords: information technology, knowledge management, organizational identification, organizational learning, knowledge-based industries, Sri Lanka.

JEL: M1, M12.

\section{$1 \quad$ Introduction}

Knowledge is considered to be the most powerful resource in the present-day business world as knowledge consists of characteristics of the inability of imitating and copying (Montequin, et al., 2006). As a result, almost all types of firms are now keeping trust on knowledge-based resources to gain the competitive advantages over similar firms.

Gaining competitive advantages through knowledge resources has become a compulsory activity of effective knowledge management (KM) in the presentday businesses, as an effective KM, always opens access to knowledge by the right person at the right time (Akhavan, et al., 2009).

Knowledge creation, storing and dissemination would probably comprise the term 'knowledge management'. However, there is no universally accepted definition for KM.

Mostly, content and context of knowledge direct the definition of KM (Koenig \& Srikantaiah, 2004). O'Leary, et al. (2001) reviews KM as a system which supports to generate, access and reuse knowledge in order to preserve and share it among working teams and individuals in the firm. This definition further emphasizes KM as a concept that can be studied only as a system connecting the organizational, individual and cultural factors.

Generally, it is believed that the individual behavior of employees is different to the team behavior of individual members of a team (Van \& Sleebos, 2006). Therefore, concepts relevant to a team and an individual member of a team such as learning in the organization have been identified as one of the most vital factors for KM.

Learning in the organization has become a key term in employee adaptation and knowledge processes, innovation and organizational development studies in individual and collective levels of employees in a firm.

One of the common findings of these studies is that managers are responsible to make the organizational environment as a learning organization, enabling employees to search for new knowledge, knowledge sharing, storing and utilization to develop the firm. Such behavior of employees would help to establish the sustainability and longevity of the firm as well. 
In one way, creating a learning culture is dependent on individual and organizational factors of the internal business environment of the firm (O'Leary, et al., 2001). In another way, the success of learning by employees is dependent upon the effectiveness of the mode of learning.

As the learning is done by the employees themselves, there is no doubt that the business environment also has a role to play.

Previous studies have adequately conceptualized about learning in the organization as a function of organizational factors. But, a few research studies have been conducted on relevant factors of individual employees' learning behavior in the firm.

Specifically, very few studies have been conducted to detail organizational learning in developing countries like Sri Lanka, where many industries are in a transitional period. Information technology industry in this regard is very specific.

In Sri Lanka, the Information Technology sector can be considered as one of the major revenue generating sources. At the same time, over the past decades, knowledge-based industries (KBIs) in Sri Lanka has been developing at a rapid space (CBSL Annual Report, 2014).

While the nature of the industry has always been dynamic and the environment ever changing. Especially, the software industry thrives on knowledge workers who learn relevant things fast and it is a focal point for the development of the IT industry (Herath \& Ranasinghe, 2011).

However, limited studies have focused on employees' learning in the firm, which is very vital for the smooth functioning of a firm in the IT sector in Sri Lanka.

Contemporary managers in the IT sector have also identified that changing the human behavior and creating a learning culture as a learning organization is a challenge (Herath \& Ranasinghe, 2011). Hence, it is worthwhile to develop this study addressing employees' learning issue with other influencing factors in KBIs in Sri Lanka.

Accordingly, the main objective of this study is reviewing the influencing factors of employees' learning in KBIs in Sri Lanka. Identifying most prone dimensions of employees' learning and the nature of relationships (positive/negative) between predictors and employees' learning in KBIs in Sri Lanka would serve as the sub-objectives of this study.

Theoretically, this study assists in enhancing the knowledge about employees' learning behavior, which is an important aspect of KM in the IT industry in general. Specifically, contextual knowledge about employee learning behavior in transitional economies like Sri Lanka would be helpful for other researchers to design their studies as well.

However, this paper is organized into five parts, namely introduction, literature review, methodology, data analysis and conclusion.

\section{$2 \quad$ Literature Review}

The literature review of this article is basically divided into three parts.

The first part is about knowledge management. The second part reserves for organizational identification and related dimensions, and the final part is about learning in the organization.

The main argument that the researcher focuses on is to build in the literature review that employees' learning behavior would be a result of other relevant individual and organizational activities. In the event of building the argument, all sub sections of the literature review provide evidence to support the main argument of the literature review.

\subsection{Knowledge Management}

$\mathrm{KM}$ is not a single process. It is a collaboration of human resources, enterprise organizational culture, information technology, methods and tools that support the organization to run their functions smoothly.

Furthermore, O'Leary, et al. (2001) describe a KM system that facilitates the creation, access and reuse of knowledge, and its main goals are to promote knowledge growth, communication, preservation and sharing.

According to Montequin, et al. (2006), making a transition of a firm that manages efficiently in all aspects of knowledge is not a trivial step. Further, knowledge and $\mathrm{KM}$ are nowadays vital areas for 
most organizations, especially those that are driven by knowledge (Montequin, et al. 2006).

According to Yu-Chung, et al. (2005) employee behavior is one of key determinant of effective KM. Employees learning in the firm and knowledge sharing behaviors are directly connected with the operation of a firm. These kinds of positive behaviors would stimulate the development and implementation of knowledge.

Implementing KM means something more than implementation of a set of IT tools; it involves changes in the organizational structure, process and culture. The first step to change from a traditional company into a $\mathrm{KM}$ is to be aware of the knowledge of the organization.

In addition to that, Yu-Chung, et al. (2005) explains that knowledge is not easily measured or audited, so organizations must manage knowledge effectively in order to take full advantage of the skills and experience inherent in their systems and structures as well as the tacit knowledge belonging to the employees of the firm.

KM can more effectively integrate and administer a firm's information technology base and assist in the development of a systematized information model.

\subsection{Organizational identification, use of digital methods and tools, knowledge sharing and turnover intention of employees}

Organizational identification (OID) is identified as a concept that can be explained, predicted and understood by the behavior of employees in an organization.

Employees generally identify the organization with their beliefs, values and principles referring to the prevailing system in the firm (Van Knippenberg \& Sleebos, 2006).

When employees have the perception of belonging to the firm to which they are attached, it is identified as OID.

Further, OID has been reviewed by Hogg and Terry (2000), as a concept of self-categorization by an employee about himself/herself in line with an overall overview of the firm.
The importance of OID has considerably grown during the recent years in studies because of its implications to organizations (Kreiner \& Ashforth, 2004). In a comprehensive study, Van Knippenberg (2000) revealed that OID is positively related with performance and organizational citizenship behavior of employees and negatively related with turnover intention of employees.

Further, an employee's positive attitudes towards the job, psychological attachment to the organization of fostering the feeling of retaining would also be enhanced by OID (Kreiner \& Ashforth, 2004). However, as far as research findings of OID are concerned, it is clear that it has been a predictor for employees' behavior in many cases.

New generation that developed with technological artefacts like different models of mobile phones, computers, video games and visual and sensible items in information technology is identified as "Digital Natives" (Palfrey \& Gasser, 2008; Prensky, 2001).

Generally, digital learning is defined as a system of radical reworking of pedagogy (Prensky, 2001) connecting to different aspects of learning. Learning in digital mode is a broader concept and it is not recognized as gaining or sharing the knowledge in any one particular place.

Accessing information through a network of peers is one of the main features of learning through the digital mode (Ito, et al., 2009).

As far as employees in firms are concerned, their learning process is mostly combined with digital artefacts. The mode of learning also matters (Jenkins, 2007). Currently, it is rare to find an organization that does not use digital equipment in the operation process. Therefore, the learning process of employees is connected with digital artefacts and mode.

Knowledge sharing is defined as an activity of sharing information, expertise, skills and attitudes among friends, communities, organizations and individuals (Eid \& Nuhu, 2011). Employees in present day organizations have been immensely influenced by social networking sites. which have influenced their learning behavior. 
Similarly, accessibility of information and knowledge by others are also making it easy for others to learn (Eid \& Nuhu, 2011). Both, accessibility and affordability of knowledge within an organization has shown to be an influence on the employee learning behavior.

Turnover intention of employees is defined as the mental readiness of employees to leave the firm. Employee turnover is reported as the main human resource issue in the IT industry in Sri Lanka and most of the other developing countries in the world. Losing skillful, competent employees who have shown better performance in the firm creates problem in teamwork and leads to incurring of extra cost for replacing the team.

However, the turnover intention is identified as part of the turnover behavior of employees (Tett \& Meyer, 1993). All the behavioral movement can be seen by employees once they have set the goal to leave the firm. Therefore, the turnover intention of employees becomes an influencing factor on the employees' learning behavior.

\subsection{Learning in the Organization}

Peter Senge in his book titled The Fifth Discipline: The Art \& Practice of the Learning Organization (1990), firstly mentions about organizational learning or learning organizations.

In this book, he identified organizational learning or learning organizations as firms in facilitating their employees to learn from the organization and make the required transformation to perform better.

The book proposed five characteristics of organizational learning, namely system thinking, personal mastery, mental model, shared vision and team learning.

Personal mastery, which is the employee's ability to grow and develop, is identified as one of the important characteristics at personal level. Employee learning, which is also recognized as a part of personal mastery, concentrates on different individual learning aspects in the firm. This concept has deepened the understanding of employee's personal vision, efforts, professional skills, knowledge and capabilities.
Senge, et al. (1994) discusses about learning in the vocation. Further, Senge, et al (1994) mentions that managers of firms should not only invest money in wealth creation, but to develop the values, skills and abilities related to the performance of employees, as employees' experience based on performance would in turn have great influence on overall firm performance.

Specifically, learning tacit knowledge by employees would enhance the individual performance as well.

\section{$3 \quad$ Methodology}

This study focused on explaining the influencing factors on employees' leaning in the firm in KBIs in Sri Lanka.

According to Sri Lanka Information Communication Technology Association (SLICTA), the current total workforce involved in the IT sector is around 60,000, of which 29,000 workers are directly involved in jobs in Sri Lanka. In addition, the IT work force categories can be mainly divided into several job categories. The sample of this survey design was based on the above information.

The survey of this purpose was conducted in 2016. The primary data was collected from 13 randomly selected KBIs that were selected using the simple random sampling technique from the list of IT related companies given by the SLICTA.

Only four main job categories, Database Administration \& Development, Systems \& Network Administration, Web Development \& Programming and Software Engineering were considered as important jobs for the study, as most of the KBIs are dominant with these jobs.

A questionnaire was developed adapting the measurements validated by other researchers on the variables of this study.

Most of the questions, other than the basic information, were in five-point Likert scale $(1=$ strongly disagree, $2=$ slightly disagree, $3=$ uncertain, $4=$ slightly agree, $5=$ strongly agree).

Measurements related to dimensions such as personal learning (Gardiner and Whiting, 1997), digital methods and mode (Lee \& Law, 2012), organizational identification (Mael \& Ashforth, 1992), 
knowledge sharing (Bock \& Kim, 2002) and three items from Wayne, et al. (1997) were used to measure the turnover intention of employees.

Finally, 141 respondents took part in the survey. Respondents for the survey were selected according to a stratified random sampling. The questionnaire was self-administered in nature and the respondents answered the questionnaire in premises of KBIs.

The fieldwork included analysis of secondary documentary sources in each organization to analyze and conclude the study.

Partial least squares regression $\left(\mathrm{X}=\mathrm{TP}^{\mathrm{T}}+\mathrm{E}\right),(\mathrm{Y}=$ $\mathrm{UQ}^{\mathrm{T}}+\mathrm{F}$ ) was performed to analyze the data.

Employees' learning in the firm served as a dependent variable and organizational identification, use of digital methods, use of digital mode, knowledge sharing of employees and turnover intention of employees served as dependent variables in this model.

In addition, a descriptive analysis of the sample was also executed.

\section{$4 \quad$ Data Analysis and Results}

Some interesting conclusions could be drawn according to the descriptive analysis of the respondents in this survey.
$22 \%$ of responses were received from the job of Database Administration \& Development. Systems \& Network Administration Officers have given 30 percent. The contribution from Web Development \& Programming and Software Engineering officers is $20 \%$ and $28 \%$, respectively. Female percentage of the sample is reported as 18 percent.

Respondent's ages ranged from 19 to 43 years. The majority of respondents ( 65 percent) is reported in the age group of 18-27 years.

At the same time, around 40 percent of respondents have reached minimum five years of work experience in their jobs. Some of the respondents have served for more than twenty years in the same company. But a majority (around 68 percent) had changed their company during the last five years.

Data analysis process began with descriptive analysis of responses. Table 1 elaborates the nature of data collected by the survey.

In the model, employees' learning in the firm served as the outcome variable and organizational identification, use digital methods, use of digital mode, knowledge sharing of employees and turnover intention of employees represented independent variables.

Table 1. Descriptive Analysis of Responses

(Source: Sample Survey, 2016)

\begin{tabular}{|l|c|c|c|c|c|}
\hline \multicolumn{1}{|c|}{ Variable } & $\begin{array}{c}\text { Obs. without } \\
\text { missing data }\end{array}$ & Minimum & Maximum & Mean & $\begin{array}{c}\text { Std. } \\
\text { deviation }\end{array}$ \\
\hline $\begin{array}{l}\text { Employees' Learning } \\
\text { in the Firm }\end{array}$ & 143 & 3.000 & 5.000 & 4.685 & 0.574 \\
\hline Organizational Identification & 143 & 4.000 & 5.000 & 4.804 & 0.398 \\
\hline Use of Digital Methods & 143 & 3.000 & 5.000 & 4.657 & 0.583 \\
\hline Use of Digital Tools & 143 & 3.000 & 5.000 & 4.629 & 0.565 \\
\hline Knowledge Sharing & 143 & 3.000 & 5.000 & 4.615 & 0.568 \\
\hline Turnover Intention & 143 & 2.000 & 5.000 & 3.734 & 0.847 \\
\hline
\end{tabular}

According to the correlation matrix of the model, four variables, namely organizational identification, use of digital methods, use of digital tools and knowledge sharing among employees have positively correlated with employees learning in the firm. 
The highest (0.749) correlation to employee's learning in the firm is reported from the use of digital methods in employees' learning process. The least value $(0.553)$ is given as knowledge sharing among employees in the firm.

Employees' turnover intentions have negatively correlated (-0.043) to employee's learning in the firm.
Almost all other variables are also correlated negatively with the turnover intention of employees. However, the minimum negative correlation of turnover intention is associated with employee's learning in the firm.

Table 2. Correlation Matrix

(Source: Sample Survey, 2016)

\begin{tabular}{|l|c|c|c|c|c|c|}
\hline \multicolumn{1}{|c|}{ Variables } & 1 & 2 & 3 & 4 & 5 & 6 \\
\hline 1. Organizational Identification & 1.000 & & & & & \\
\hline 2. Use of Digital Methods & 0.589 & 1.000 & & & & \\
\hline 3. Use of Digital Tools & 0.489 & 0.574 & 1.000 & & & \\
\hline 4. Knowledge Sharing & 0.381 & 0.322 & 0.299 & 1.000 & & \\
\hline $\begin{array}{l}\text { 5. Turnover Intention } \\
\text { 6. Employees' Learning } \\
\text { in the Firm }\end{array}$ & -0.134 & -0.015 & -0.148 & -0.068 & 1.000 & \\
\hline
\end{tabular}

Partial least squares (PLS) regression model results showed the quality of the model as $\mathrm{Q}^{2}$ cum $=0.820$, $\mathrm{R}^{2} \mathrm{Y}$ cum $=0.826$ and $\mathrm{R}^{2} \mathrm{X}$ cum $=0.497 . \mathrm{R}^{2}$ of the model is $0.761(\mathrm{SD}=0.281)$. However, the PLS model has calculated the coefficients of each varia- ble as shown in table 03. Accordingly, the intercept is reported as -1.120 and turnover intention of employees' negative value. All other values are reported as positive coefficients.

Table 3. Coefficients (Variable Employees' Learning in the Firm)

(Source: Sample Survey, 2016)

\begin{tabular}{|l|c|c|c|c|}
\hline \multicolumn{1}{|c|}{ Variable } & Coefficient & Std. deviation & $\begin{array}{c}\text { Lower bound } \\
(95 \%)\end{array}$ & $\begin{array}{c}\text { Upper bound } \\
(95 \%)\end{array}$ \\
\hline Intercept & -1.120 & 0.297 & -1.706 & -0.533 \\
\hline Organizational Identification & 0.382 & 0.034 & 0.315 & 0.449 \\
\hline Use of Digital Methods & 0.314 & 0.030 & 0.255 & 0.374 \\
\hline Use of Digital Tools & 0.322 & 0.033 & 0.257 & 0.388 \\
\hline Knowledge Sharing & 0.229 & 0.044 & 0.142 & 0.317 \\
\hline Turnover intention & -0.012 & 0.023 & -0.058 & 0.034 \\
\hline
\end{tabular}


When all independent variables are prioritized based on the influencing ability to employees' learning in the firm, the model has concluded by providing the results as given in Fig. 1.
Accordingly, the most influencing factor is identified as use of digital methods (1.252) and least influencing factor is reported as turnover intention (0.072). The second least important factor is depicted as knowledge sharing (0.891).

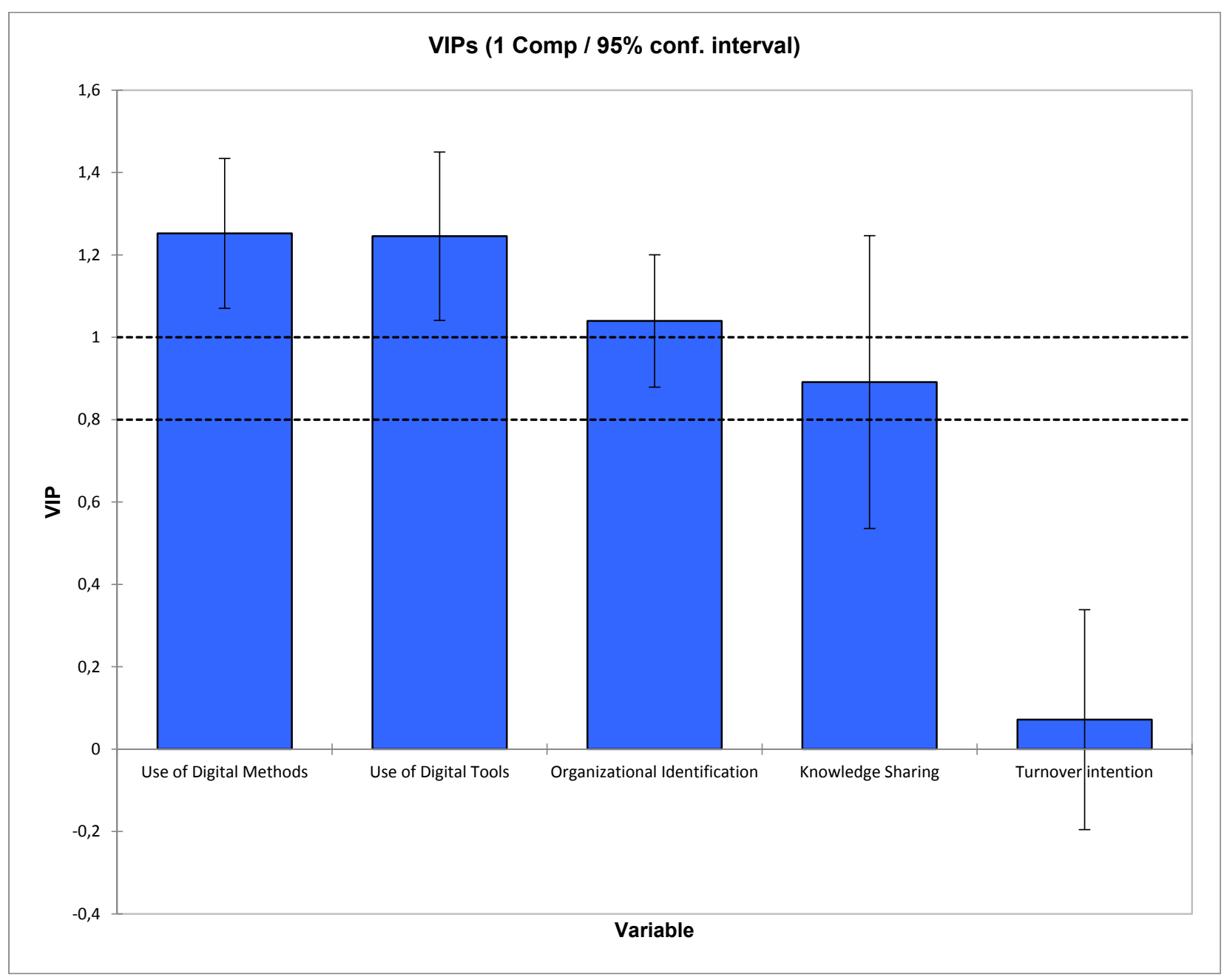

Figure 1. Variables Important in the Projection

(Source: Sample Survey, 2016)

At the same time, the results indicate the standardized coefficient in case of employees' learning in the firm as shown in Fig. 2.

Accordingly, a minus coefficient is reported for the turnover intention of employees.

This analysis indicated several findings:

- Firstly, it was recognized that employees' learning is positively correlated with organizational identification, use of digital methods, use of digi- tal tools and knowledge sharing among employees. However, turnover intention negatively correlated to employees' learning in the firm.

- Secondly, the higher influence was made respectively by the use of digital methods and the use of the digital tool in the learning process. A minimum influence was reported by turnover intention of employees in their learning process in the firm. 




Figure 2. Variables Important in the Projection

(Source: Sample Survey, 2016)

\section{5}

\section{Conclusion}

According to the analysis, employee identification, use of digital methods of learning, use of digital tools in learning and knowledge sharing among employees have shown a positive correlation to employees' learning in the firm.

The digital mode of learning and use of digital artefacts have shown a strong correlation to employees' learning, concluding the current trend in the IT sector. Once the employees in the IT sector get used to working with technology, they experience everlasting changes in equipment, technology and methods.

As a result, the continuous learning process has become compulsory for employees. However, a positive effect is seen when learning takes place through digital methods and tools.

Provision and establishment of new methods, equipment and technologies through digital methods and tools in KBIs would probably make it easier to develop the firm as a learning organization.

Also, this study was carried out under limitations. The small sample size and selecting respondents only from four job categories are the limitations of this study.
Also, the KBIs have had differences as the IT industry is highly diversified. Accordingly, the selection of the sample from a wider perspective covering more KBIs, job categories and respondents would make these kinds of studies more solid and stable.

The use of the model (PLS) had some limitations in interpreting relationships among variables as the data appeared on Likert Scale. Extending PLS to Structural Equation Modelling (SEM) would eliminate that issue of advancing the analysis to be more thorough. Therefore, eradicating of one of these limitations would direct the future researcher to analyze the same research in detail.

Research findings of this study implicate a few important aspects to practice:

- most firms in the IT sector are trying to convert their firms as learning organizations to gain competitive advantages and innovations,

- KBIs in present day competition can't survive in the long term without having an energetic, motivated, knowledgeable and dedicated workforce who can make the organization change as per the requirement of the society at large,

- knowing the learning behavior of workforce and employee's learning related factors in the firm is a primary step in the conversion process of a firm as a learning organization. 
Therefore, this study would fulfil that requirement of managers, owners, governors and policy makers who are considering making their firms learning organizations in the IT sector in general.

Author of this article is grateful to the Internal Grant Agency of FaME TBU No. IGA/FaME/2016/001: Enhancing Business Performance through Employees' Knowledge Sharing, for financial support to carry out this research.

\section{References}

[1] Akhavan, P., Hosnavi, R., Sanjaghi, M.E., 2009. Identification of Knowledge Management Critical Success Factors in Iranian Academic Research Centers. Education Business and Society: Contemporary Middle Eastern Issues, Emerald Group Publishing Limited. 2(4), pp.276-288. https://doi.org/10.1108/17537980911001107.

[2] Annual Report (2014). Central Bank of Sri Lanka, Colombo, Sri Lanka.

[3] Bock, G.W., Kim, Y.G., 2002. Breaking the Myths of Rewards: An Exploratory Study of Attitudes about Knowledge Sharing. Information Resources Management Journal, 15(2), pp.1421. https://doi.org/10.4018/irmj.2002040102.

[4] Eid, M., Nuhu, N.A., 2011. Impact of Learning Culture and Information Technology Use on Knowledge Sharing of Saudi Students. Knowledge Management Research and Practice, 9(1), pp.48-57. https://doi.org/10.1057/kmrp. 2010.25 .

[5] Gardiner, P., Whiting, P., 1997. Success Factors in Learning Organizations: An Empirical Study. Industrial and Commercial Training, 29(2), pp.41-48.

[6] Herath, H.M.T.S., Ranasinghe, A., 2011. Labour Market Prospects for Business Graduates in Sri Lanka. International Journal of Social Science and Humanity, 1(1), pp.26-30. https://doi.org/ 10.7763/ijssh.2011.v1.5.

[7] Hogg, M.A., Terry, D.J., 2000. Social Identity and Self-Categorization Processes in Organizational Context. Academy of Management Review, 25, pp.121-140. https://doi.org/10.2307/ 259266 .
[8] Ito, M., Baumer, S., Bittanti, M., Boyd, D., Cody, R., Herr-Stephenson., 2009. Hanging Out, Messing Around, and Geeking Out: Kids Living and Learning with New Media. Cambridge: The MIT Press.

[9] Jenkins, H., 2007. Reconsidering Digital Immigrants [Blog Post].

[10] Koenig, E.D., Srikantaiah, T.K., 2004. Knowledge Management Lessons Learned - What Works and What Doesn't. Information Today, 2, pp.55-69. https://doi.org/10.5860/choice. 420349 .

[11] Kreiner, G.E., \& Ashforth, B.E. 2004. Evidence Toward an Expanded Model of Organizational Identification. Journal of Organizational Behavior, 25, pp.1-27. https://doi.org/10.1002/job.234.

[12] Lee H.N., Law, R., 2012. Technology-mediated Management Learning in Hospitality Organisations. International Journal of Hospitality Management, 31, pp.451-457. https://doi.org/10. 1016/j.ijhm. 2011.07.003.

[13] Mael, F., Ashforth, B.E., 1992. Alumni and Their Alma Mater: A Partial Test of the Reformulated Model of Organizational Identification. Journal of Organizational Behavior, 13, pp.103123. https://doi.org/10.1002/job.4030130202.

[14] Montequin, V.R., Fernández, F.O., Cabal, V.A., Gutierrez, N.R., 2006. An Integrated Framework for Intellectual Capital Measurement and Knowledge Management Implementation in Small and Medium-sized Enterprises. Journal of Information Science, 32(6), pp.525-538. https://doi.org/10.1177/0165551506067127.

[15] O’Leary, D.E., Studer, R., 2001. Knowledge Management: An Interdisciplinary Approach. IEEE Intelligent Systems, January/February, 16 (1). https://doi.org/10.12955/ejbe.v5i0.165.

[16] Palfrey, J., Gasser, U., 2008. Born Digital: Understanding the First Generation of Digital Natives. New York: Basic Books.

[17] Prensky, M., 2001. Digital Natives, Digital Immigrants [pdf]. On the Horizon, Vol. 9. MCB University Press.

[18] Senge, P.M., 1990. The Fifth Discipline. New York: Doubleday Publ. 
[19] Senge, P.M., Roberts, C., Ross, R.B., Smith, B.J., Kleiner, A., 1994. The Fifth Discipline Fieldbook. New York: Doubleday Publications.

[20] Tett, R.P., Meyer, J.P., 1993. Job Satisfaction, Organizational Commitment, Turnover Intention, and Turnover: Path Analyses Based on Meta-analytic Findings. Personnel Psychology, 1(46), 259-293. http://dx.doi.org/10.1111/j.17446570 .1993. tb00874.x.

[21] Van Knippenberg, D., Sleebos, E., 2006. Organizational Identification Versus Organizational Commitment: Self-definition, Social Exchange and Job Attitudes. Journal of Organizational
Behavior, 27, 571-584. https://doi.org/10.1002 /job.359.

[22] Wayne, S.J., Shore, L.M., Liden, R.C., 1997. Perceived Organizational Support and Leadermember Exchange: A social Exchange Perspective. The Academy of Management Journal, 40(1), 82-111. http://dx.doi.org/10.2307/257021.

[23] Yu-Chung, H., Shi-Ming H., Quo-Pin L., MeiLing -Tsai, 2005. Critical Factors in Adopting a Knowledge Management System for the Pharmaceutical Industry. Industrial Management \& Data Systems, 105(2), pp.164-183. https://doi. org/10.1108/02635570510583307. 